\title{
Reformulando los géneros, reformulando la violencia: una teoría queer de la violencia
}

\author{
Reformulating Genders, Reformulating Violence. \\ A Queer Theory of Violence
}

Reseñado por Juan Martínez Gil* Universitat de Barcelona, Barcelona, España.

Recibida: 8 de diciembre de 2018. Aprobada: 19 de febrero de 2019 .

10.25100/lamanzanadeladiscordia.v14i1.8064

Reseña

Palabras clave: Estudios queer; violencia de género; violencia doméstica; feminismo.

Keywords: Queer studies; gender violence; domestic violence; feminism.

Reseña del libro: Arisó, Olga y Mérida, Rafael. (2010). Los géneros de la violencia. Una reflexión queer sobre la “violencia de género”. Barcelona-Madrid, España: Egales.

Olga Arisó Sinués es educadora social, licenciada en Filosofía y máster en Estudios de Género. Durante los últimos años ha trabajado como técnica en el Ayuntamiento de Barcelona, donde ha desarrollado y gestionado, junto a sus compañeras, diversos proyectos de intervención social con y para mujeres, en especial contra la violencia machista. También ha sido directora del Centre d'Informació i Recursos per a les Dones (CIRD).

Rafael Manuel Mérida Jiménez es doctor en Filología Hispánica, profesor Serra Húnter en la Facultad de Letras de la Universitat de Lleida, investigador del Centre ADHUC y docente en el máster del Institut Interuniversitari d'Estudis de Dones i Gènere (IIEDG). Es autor de diversas monografias como Transbarcelonas. Género y sexualidad en la España del siglo XX (2016) $y$ editor de las antologías Sexualidades transgresoras (2002) y Manifiestos gays, lesbianos y queer (2009).

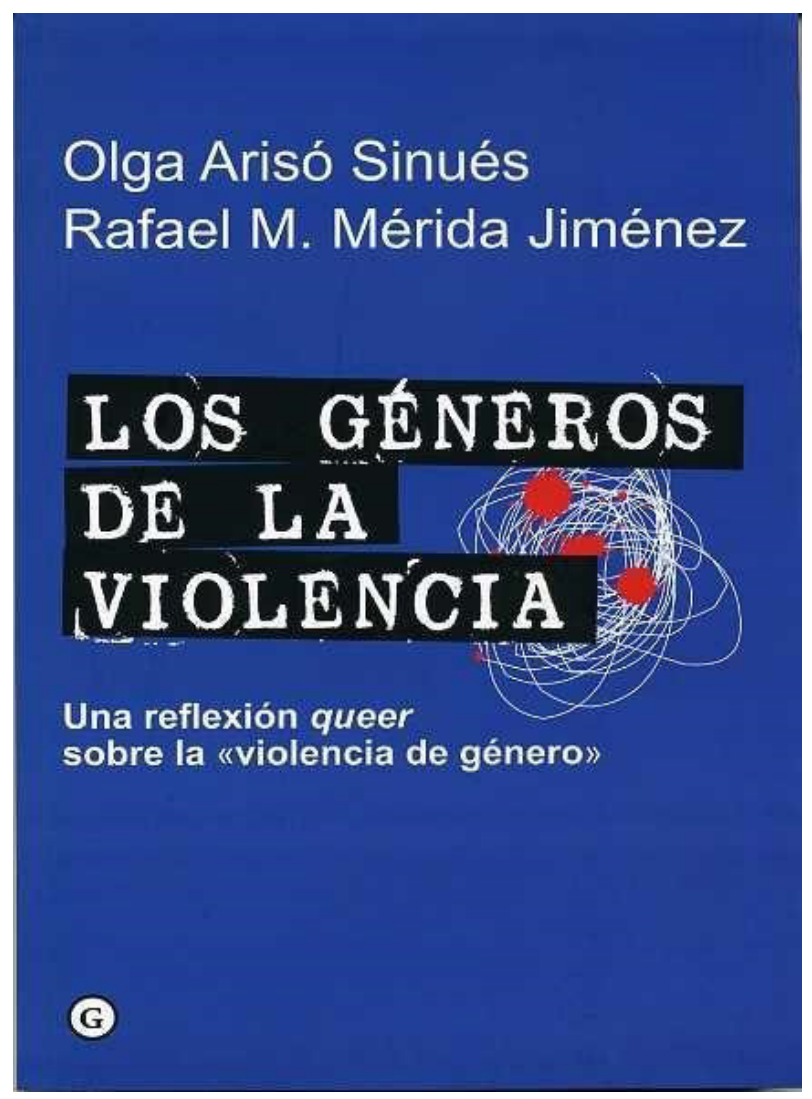

Figura 1. Carátula del libro Los géneros de la violencia. Una reflexión queer sobre "la violencia de género" Fuente: Universidad de Barcelona, Adhuc. (s.f.)

\footnotetext{
* Graduado en Estudios Hispánicos en la Universitat de València y Máster en Profesor de Secundaria por la Universitas Miguel Hernández de Elche. Actualmente es estudiante del máster en Construcción y representación de identidades culturales en la Universidad de Barcelona. Correo electrónico: juanmgi195@gmail.com. ORCID:0000-0002-7712-7910
} 
Ante las diferentes perspectivas y términos que sirven para nombrar y describirla violencia que sufrimos las personas por motivos sexuales o de género ("violencia contra las mujeres", "violencia machista", "violencia patriarcal" o "violencia de género", entre otros)1@s autor@s $\mathrm{s}^{1}$ de este texto se plantean: ¿qué es realmente la "violencia de género"? ¿Cómo la aborda y ha abordado el feminismo? ¿Cómo debería hacerlo? Olga Arisó es técnica de igualdad en el Ayuntamiento de Barcelona donde trabaja diseñando proyectos de intervención social para víctimas de "violencia machista" y Rafael M. Mérida es profesor de literatura española y estudios de género e investigador en la Universitat de Lleida. Como indican en el volumen, a amb@s les une una gran amistad y el interés por profundizar y debatir diferentes cuestiones del feminismo. Fruto de su diálogo y reflexión interdisciplinaria nace el volumen aquí reseñado.

En Los géneros de la violencia se pretende demostrar cómo la violencia que llamamos "de género" responde a la estructura misma de la sociedad y a su forma de concebir culturalmente el mundo y las relaciones sociales. A raíz de esta exposición y apoyándose en diferentes enfoques teóricos del feminismo,1@s autor@s proponen repensar políticas individuales y colectivas más liberadoras en las que la diferencia a la norma no implique necesariamente una situación de agresión. Para ello se sirven de las reflexiones particulares de algunas autoras, estructurando su obra en cuatro secciones.

La primera parte del volumen tiene por título "La violencia contra las mujeres" (pp. 13-48) y describe las estrategias y luchas políticas de los movimientos emancipatorios correspondientes a la primera y segunda ola del feminismo, así como algunas de sus polémicas. Una vez planteada esta breve genealogía feminista,1@s autor@s repasan la concepción de la "violencia de género" en base a las argumentaciones de este feminismo anterior a la década de 1970. Por ello, muy acertadamente, llaman al capítulo "La violencia contra las mujeres", título que refleja perfectamente la falta de cuestionamiento de la identidad "mujer" como sujeto en este feminismo.
El capítulo repasa algunas consideraciones feministas como la necesidad de convertir lo privado en político para visibilizar la violencia -muchas veces doméstica o familiar-, así como también propone métodos para analizar estructuralmente el sometimiento a las mujeres, como el "modelo ecológico" de Nuria Grau Santamaría. Por otro lado, se incide en la lógica interna de la dominación con base a la relación hegeliana amo-esclavo a través de un listado de las actitudes masculinas que la fomentan y de los impedimentos con los que se encuentra el feminismo para erradicarlas. En este punto la obra insiste -con gran fortuna a mi parecer- en la necesidad de visibilizar nuevas masculinidades que escapen de estos modelos para empezar una regeneración social más allá de la lógica del control patriarcal. Una lógica en la que la mujer es un ser "para otros", alimentada y reproducida por la construcción social del amor.

En la segunda parte, "Feminismos y género" (pp. 49-68) continúa esta genealogía feminista a partir de la década de 1970, cuando el feminismo entra en el debate público. Se recogen los puntos comunes de los recién denominados estudios "de género" y los nuevos enfoques que proponen. Se relata cómo a raíz del pensamiento sobre el parentesco de Lévi-Strauss, algunas feministas como Monique Wittig y Teresa de Lauretis comenzarán a problematizarla división "naturaleza"/“cultura". De la primera, Arisó y Mérida destacan su noción de "pensamiento heterosexual" como elemento totalizador de la experiencia humana y su insistencia en que la subversión de este pensamiento debe empezar por el lenguaje. Aún hoy en día existen grandes debates en torno a esta cuestión en lengua española, como por ejemplo el uso del masculino genérico que1@smism@s autor@s boicotean en su práctica escritural con el signo de la arroba (@). También ponen el foco en Teresa De Lauretis (2000) y su teorización sobre las "tecnologías de género" que producen y reproducen el género en la sociedad y sus cuerpos. De Lauretis explicita la necesidad de pensarnos fuera de este binomio y el peligro que corre el feminismo de caer en él.

1 En el libro,amb@s autor@s escriben con arroba (@) como fórmula de género no marcado. He decidido respetar su uso para la escritura de la presente reseña, a pesar de que la arroba no sea reconocido como un signo lingüístico por la Real Academia Española. 
El género en disputa de Judith Butler (2001) es la obra que centra la tercera parte del volumen y que incluso le da nombre: "El género en disputa" (pp. 69-110). En esta parte se comenta detalladamente la teoría que propone la filósofa estadounidense quien, retomando a Wittig (2006) y De Lauretis (2000), realiza una autocrítica desde y hacia el feminismo. La exposición de Butler según la explican Arisó y Mérida, pretende, por un lado, armar teóricamente la desnaturalización del género hasta sus últimas consecuencias, y por otro, elaborar una teoría de la performatividad que explique su reproducción. Butler carga contra los esencialismos de los movimientos identitarios (feminismos y movimientos LGTBQ) y sugiere que hay que abrir las posibilidades del género para escapar del binarismo $\mathrm{y}$ de la heterosexualidad obligatoria. Asimismo, se plantea las posibilidades reales de vivir el género de una manera distinta y comprueba cómo el resultado siempre es la violencia para los cuerpos inteligibles o no binarios (como el cuerpo travesti).

Aunque Butler (2001) reconoce la lucha feminista como necesaria para conseguir la legitimidad política, insiste en que desnaturalizar el género implica golpear a la base del feminismo y su noción de "mujer". ¿Cómo es posible pretender la emancipación de unas estructuras de poder que te crean a ti como sujeto? De esto trata lo que considera la "ficción fundacional" del ser: cómo se ha creado discursivamente la indisolubilidad del sexo y el género para garantizar los fines reproductivos. Por otro lado, critica la noción universalista del feminismo que apela a un supuesto "patriarcado universal", ignorando que existan unos contextos determinados en que las mujeres devienen. En esta tesis encontramos la base de la interseccionalidad que los estudios de género reivindican actualmente. En general, Butler aboga por un discurso posidentitario -pues toda identidad implica una violencia hacia el otroque será la base sobre la que navegará la tercera ola a partir de este texto fundacional que1@s autor@s han querido sintetizar.

Una vez expuestos los presupuestos teóricos de la tercera ola en el segundo y tercer capítulo, Arisó y Mérida pretenden volcar todo este conocimiento en la reflexión en torno a la violencia como han trabajado en el capítulo 1. Esta última parte,
"Violencias y géneros" (pp. 111-136) es sin duda la más original del libro y la que merece nuestra mayor atención porque resulta de la aplicación propia de1@s autor@s de todos los preceptos del feminismo de la tercera ola aplicados al concepto "violencia de género". Aquí recuperan las "tecnologías de género" de De Lauretis (2000) como creadoras de la violencia estructural de la sociedad a nivel político y cognitivo. Arisó y Mérida señalan cómo la creación de individuos binarios comporta la "virilización" del varón y la naturalización de unos "instintos" de violencia que desembocan en la dominación a su otro, la mujer, privada por descompensación de estos mismos "instintos". Es de esta forma como el mandato biológico de la genitalidad construye todo un aparato discursivo en el sistema de sexo-género que legitima la violencia.

Butler (2001) incide en la violencia contenida dentro del "pensamiento heterosexual" formulado por Wittig (2006) para el establecimiento de una categoría de lo humano y lo no-humano, al tiempo que señala la necesidad de abrir el concepto de violencia de género que tradicionalmente reivindica el feminismo al incluir, por ejemplo, los suicidios de adolescentes queer. L@s autor@s inciden en la necesidad de reivindicar también estas violencias invisibilizadas dentro del feminismo a las que ellos llaman "la otra violencia de género". El feminismo pues, tiene que salir de sí mismo y de la categoría esencialista de mujer para aliarse con las otras exclusiones. Tiene que abandonar, en definitiva, su “ficción reguladora" (p. 87).

Así, la tercera ola y la teoría queer nos enseñan que necesitamos abrir el concepto de "violencia de género" para que deje de ser una "cosa de mujeres", ya que realmente nos afecta a tod@s. Se trata de una "violencia estructural" al mismo tiempo que de una "violencia ilegítima" porque se establece sobre la ficción del sistema de género, un sistema que debemos destruir antes de que acabe con nosotr@s. Pero ¿cómo podemos hacerlo? ¿Cómo podemos crear políticas individuales y colectivas que nos posibiliten opciones vitales más liberadoras? El volumen recoge varias propuestas diseminadas entre sus páginas, desde las nuevas masculinidades o el uso del lenguaje que comentábamos, hasta el mismo acto de contar un cuento, que puede ser subversivo y 
cambiar los modelos de género establecidos. La obra problematiza también el término "identidad" como posible generador de violencia (se hace referencia a las "identidades asesinas" de Amin Maalouf) y la necesidad del feminismo de superar el activismo identitario.

En conclusión, Arisó y Mérida nos proponen posiciones teóricas para repensar la violencia desde diferentes perspectivas feministas.Amb@s inciden en la necesidad de queerizar la «violencia de género» para abrir los términos y las categorías que nos oprimen y así destruirlas fuera de su binarismo, de forma que "a todos y a todas nos compete definir y defender lo humano [...] transformar el orden establecido subviertiendo las identidades y defendiendo un nuevo contrato social" (p. 135). A pesar de que el volumen pueda resultar fácil o demasiado descriptivo para una persona ya cultivada en el feminismo, -pues más de medio libro se centra en explicar las teorías de De Lauretis, Wittig y Butler en lugar de trabajar las suyas propias-, en realidad resulta interesante la aproximación que a ellas se realiza poniendo el foco siempre en el papel de la violencia dentro de las obras. A su vez, en la última parte del volumen encontramos un trabajo teórico más elaborado, que enlaza todas las ideas anteriores para dar respuesta a una auténtica teorización queer sobre la violencia -como promete el subtítulo del volumen- así como su esfuerzo en proponer, imaginar y formular posibles escapatorias. Quizás es en este punto donde mejor encontramos a Olga Arisó como trabajadora de campo de la violencia de género, siendo uno de los grandes aciertos de este tipo de enfoques interdisciplinarios, tan necesarios como escasos, donde la teoría hace la práctica y la práctica la teoría.

\section{Referencias bibliográficas}

Arisó, Olga., y Mérida, Rafael. (2010). Los géneros de la violencia. Una reflexión queer sobre la "violencia de género”. Barcelona-Madrid, España: Egales.

Butler, Judith. (2001). El género en disputa. El feminismo y la subversión de la identidad. México D.F., México: Paidós.

De Lauretis, Teresa. (Ed.). (2000). "Tecnologías del género". En Diferencias. Etapas de un camino a través del feminismo (pp. 33-69). Madrid, España: Horas y Horas.

Wittig, Monique. (2006). El pensamiento heterosexual y otros ensayos. Barcelona-Madrid, España: Egales. 